Preparing for Uganda: Anticipating the Intersections of Gender, Race, and Nationality in Transcultural Leadership Development Research

\author{
Dr. Angela D. Carter \\ Clemson University, Clemson, South Carolina
}




\section{Preparing for Uganda: Anticipating the Intersections of Gender, Race, and Nationality in Transcultural Leadership Development Research}

Transcultural research — that is, comparative research that seeks to bridge shared interests and common values within and across national cultural and national borders — can be fraught with challenges (McArt \& Brown, 1990; Slimbach, 2005). On one hand, the researcher can encounter risk in the different languages, cultures, traditions, and resources as it relates to traveling across borders, not to mention the potential research barriers of reliability, subjectivity, and trustworthiness. On the other hand, the researcher can find reward in opening up to "opportunities for acquiring a set of personal attitudes, social sensitivities, and intellectual skills" that are rarely, if ever, realized if not by venturing outside of your comfort zone (Slimbach, 2005, p 207). Interestingly, it is this very combination of trepidation and possibility, mixed with an internalized mantra and wholehearted belief that with change comes learning, and with learning comes change, that I find exhilarating about traveling to Uganda to engage in faculty leadership development research. The research is novel in this setting, and holds promise to expand our knowledge and practice of women's leadership, gender equity, and organization learning and development in an African higher education context. As I make necessary preparations to begin the journey to Uganda, perhaps the most difficult things to attend to are my own thoughts and reflections as a Black woman, a Feminist, and American on a first-time visit to the continent of Africa for leadership research.

In this article, I seek to accomplish a number of interrelated goals. The first is to lay the foundation and context for my upcoming research, as gender equitable leadership remains an under researched subject in Uganda, a developing but resource-rich country. Next, is to explore the comparatively sparse literature that exists on the confluence of faculty development that 
includes gender equity leadership specifically in a Ugandan higher education context. In the article, I also anticipate the political and cultural journey that lie ahead for me as I examine my subjectivity and embark on a leadership research journey in the gendered, patriarchal environment of Ugandan universities. The article concludes by drawing from transcultural and international research traditions to emphasize the best practices for such collaborative processes of conducting action research internationally.

\section{Gender Equity Context}

Women around the globe encounter barriers despite some having the education, preparation, and the will to assume leadership roles (Bierema, 2016). As compared to men, women are disproportionately concentrated in lower level and lower-authoritative leadership positions (Northouse, 2014) in which opportunities for promotion to top positions are limited (Tyson, 2014). This experience is known as the gender gap, where disparate opportunities, status, and attitudes exist between men and women. Under the auspices of gender gap are also a number of issues that require attention, such as gender pay gap, gender segregation, quality of work, sexual harassment, sex (in)equality, gendered hierarchy, power relations, and male dominated work cultures (Meir zu Selhausen, 2015). The World Economic Forum's 2017 Global Gender Gap Index advanced that women receive $10 \%$ to $30 \%$ less pay than men for work of equal value. Startlingly, at the current rate of progress, it will take 217 years, or until the year 2237, to close the gender gap worldwide (World Economic Index, 2017).

The gender gap currently costs sub-Saharan Africa over $\$ 95$ billion each year (Africa Human Development Report, 2016). In Uganda, woman enjoy just $70 \%$ of the human development outcomes of men, mostly due to lower levels of education, and lower labor force participation. There exists conflicting data on gender pay gap in Uganda: some report that the 
average Ugandan woman makes around \$1 for each $\$ 2.50$ made by a man (Gender Gap, n.d.), while other sources note near equal pay between female and male Ugandans (Gender Pay Gap in Uganda, 2018). Contradictory data aside, positive trends show that women in Uganda are some of the world's most prolific entrepreneurs, starting businesses at rates equal to men (Kermeliotis \& Veselinovic, 2014) and also demonstrate promising numbers in politics, where over $35 \%$ of Parliament members are women (Obong, 2015).

Uganda has historically been one of the most resource rich countries, yet remains one of the poorest and the least developed nations of the world (Torvik, 2009). The current population of Uganda stands at 42.7 million people, up from 32 million in 2010 (World Bank, 2019). A landlocked country in East Africa, Uganda is "bordered to the east by Kenya, to the north by South Sudan, to the west by the Democratic Republic of the Congo, to the south west by Rwanda, and to the south by Tanzania" (Mugisha Baine, 2010). Since gaining independence from colonial rule in 1962, the country has struggled to remain free of ethnic and political conflicts, which have significantly stalled national development and improvement of people's quality of life (Odoi-Tanga, 2009). In Uganda, as in several other neighboring African countries, strategies and policies have been adopted to lessen gender educational inequity, including a reduction in school costs through providing universal primary and secondary education and privatization/liberalization of the education sector including higher education (Mugisha Baine, 2010). Although there has been some progress in increasing enrolment at all levels of education in Uganda (Makere University 2004), significant gender disparities remain in Uganda's education system, especially higher education (Mugisha Baine, 2010).

For women, education is the key to achieving socio-economic parity, sustainable economic development, poverty reduction, better nutrition and better health, as well as social 
progress and justice (Mugisha Baine, 2010). Moreover, quality education higher education is tapped as the most significant force for alleviating poverty, improving health and livelihoods, increasing prosperity, and shaping more inclusive, sustainable, and peaceful societies (Wachira, 2014). Liberation for African women depends not only on providing unlimited access to education, but also on reframing education as not only for individual empowerment and capacity development, but also as a means to elevate in formal society (Bolden \& Kirk, 2009).

\section{Higher Education in Uganda}

Starting in 1922, the Ugandan government solely provided technical and trade education at Makerere University, the only university in the country at that time, and became an undergraduate and graduate degree granting institution university in 1970 (Makerere, 2017). The purpose of higher education then was to fill a human resource gap for the colonial and postindependence governments (Mugisha Baine, 2010). Throughout the colonial period and the postindependence era, university education was free for all who qualified and remained so until 1988 when an Act of Parliament set up the first private university. Since 1988, there has been a rapid expansion of private universities such that the government found it imperative to enact the Universities and Other Tertiary Institutions Act 2001 to regulate the establishment and running of institutions of higher education (Mugisha Baine, 2010). Currently across the five regions Uganda has 26 universities, five public and 21 privately owned. (NCHE, 2018).

Not surprisingly, universities in Uganda were not founded with women and girls in mind (Kwesiga 2002; Mannathoko, 1995) and remain decidedly patriarchal. Makerere was founded in 1922, and the first women were not admitted until 23 years later in 1945 with separate curricula from males (Kwesiga 2002; Makerere University, 2000). Although academies were challenged to radically accelerate their approaches to empower women faculty, encourage their development 
as leaders, and address the massive gender gaps in students and staff on most campuses (Bennett, 2002), there has been little focus on building and sustaining effective governance to meet the challenges of the rapidly changing environment (Onsongo, 2009; Asiimwe \& Steyn, 2014).

In 2017-2018, the student population of women in higher education institutions remained at $45.91 \%$ (NCHE, 2018), and only 3\% of Uganda's professoriate were women, a fact that has changed little since the early 2000's (Mama, 2003). Women faculty who hold senior leadership positions are grossly underrepresented and significant gender differences remain at faculty and administrative levels, as well as across disciplines. Men still account for most of the senior academic staff in Ugandan universities and are overrepresented in fields such as business, science, technology, and engineering. Gender inequalities have persisted in universities' institutional profiles, in their cultures, and in their core business of teaching and research (Mama, 2006). The espoused ideals are that of gender-neutral and co-educational spaces for learning and knowledge production, although pragmatically, these systems tend to be gendered and unequal, with academic access and benefits denied to women (Assié-Lumumba, 2006).

Other structural issues are present as it relates to gender focused research. With the exception of a gender studies department at Makerere University, there is little gender-focused research being carried out elsewhere in Uganda (Mugisha Baine, 2010), and research biases in favor of quantitative methods can be seen as an affront to gender-focused research that tends to use qualitative or mixed methodology (Mugisha Baine, 2010). Additionally, students lack a mechanism for engaging in critical questioning to appreciate the complex issues surrounding gender and other inequalities (Mugisha Baine, 2010). Universities should be seen as centers of knowledge and innovation yet continue to be challenged to be more flexible and outward looking (Asiimwe \& Steyn, 2014). 
Currently, universities in Uganda have nothing to lose if they fail to run their institutions according to gender equality principles (e.g. the rules governing the hiring, promotion and firing of staff; assessment of professors, lecturers and tutorial assistants, do not affect men and women in the same way) (Mugisha Baine, 2010). Ideally, national educational oversight organizations, like the NCHE, would be on the forefront of promoting gender equity, however, affirmative action remains one of the only means to promote gender equity, and without stronger commitment to measures of quality, enforcement, and monitoring, gender inclusivity will not get the attention it deserves (NCHE, 2007). Seemingly, this failure stems from a lack of knowledge on how to proceed actively seek information to follow through gender equality issues (Mugisha Baine, 2010).

For higher education to remain relevant, "new forms of leadership and new leaders [will be] called upon to navigate through these turbulent times" (Block \& Smith, 2016; Hannum, Muhly, Schockley-Zalaback, \& White, 2015, p. 65). Therefore, efforts to support leadership education and other development opportunities, such as mentoring, coaching, and leadership development would be expected to positively contribute to sustainable and relevant academic institutions. Having female presence in top positions helps the entire organization, as “establishments with higher proportions of female managers [were] markedly less gender segregated" (Huffman, Cohen, \& Pearlman, 2010, p 267). Further, organizations that acknowledge gender diversity as a business imperative and recognize gender diversity as a strategic necessity have a better chance at surviving in a landscape where uncertainty, constant change, increased competition, frequent restructuring, downsizing, and budget cuts are becoming common place (Warrick, 2011). All of this suggests there is significant room for growth both in 
the numbers of women faculty, and in the establishment of meaningful faculty development policy that lead to individual capacity development and systemic change.

\section{Development in Higher Education Contexts}

It is true that higher educational institutions in the Sub Saharan countries were established to provide education, engage in theoretical and practical research that can strongly connect to industrial development, and enhance sustainable socioeconomic development (Asamoah \& Mackin, 2015). Also true is that most universities in Uganda are accused of producing graduates who are not relevant to the country's labor market needs, and who are ill prepared for the ever changing and competitive knowledge economy (Kasule, Wesselink, \& Mulder, 2014). Much of the literature (e.g. Association of African Universities, 2013; Mayer, Wilde, Dinku, Fedrowitz, Shitemi, Wahlers \& Ziegel, 2011; Sawyerr, 2004a; Yizengaw, 2008) point to the challenges connected with the scarcity of skilled teaching staff, including:

poor governance, leadership and management, inadequate finance and inability to diversify funding, poor and dilapidated institutional facilities and equipment, deteriorating quality and relevance of teaching and research, limited capacity for research, innovation, knowledge generation and adaptation capabilities; and irrelevance of the educational programmes to the labour market, consequently, leading to high graduate unemployment (Kasule, 2015).

Universities in Uganda have been known to also duplicate courses in order to attract more

students. While producing more revenue for the university, this ignore the lessened market demand for graduates and the socio-economic development needs of the country (Amme \& Agaba, 2014; Mamdani, 2007). This dichotomy is due to mismatch of ideals and the knowledge of how change is best approached in African higher education contexts, and how to begin the conversation of addressing the gender, leadership, and faculty development gap in Ugandan universities. One way to examine ways to affect change is in understanding faculty development as a capacity development exercise. What we typically think of as capacity refers to the increase 
in skills and knowledge required for individuals and organizations to perform more effectively. Capacity development more broadly proposes to equip individuals, institutions, regions or countries with the attitudes, values and behaviors needed to bring about change and progress. (Franz et al, 2019; Morgan, 2005).

Another approach could begin with recognizing these as adaptive, rather than technical problems. Adaptive problems are pressing and deep, involve new ways of thinking and engagement with multiple stakeholders, and generally require people to change their habits, priorities, and values, as opposed to technical problems. Technical problems are easy to identify, often lend themselves to quick solutions, and can be quickly dispatched by an authority or expert (Heifetz, Linsky, \& Groshow, 2009). Narrowing the gender leadership gap will require adaptive work to effect changes in policies, organizational practices, and attitudes (Tyson, 2014). Not only is it imperative that women have economic power, personal agency, and unfettered opportunity, but organizations themselves need both culture and attitude transformation to meet the adaptive challenges inherent in the volatility of the organizational climate, changing leader roles, and shifting organizational practices (Nica, 2013).

\section{Faculty Development}

Higher education, increasingly the context for development work, is now a global and international enterprise. Certainly, efforts to support and enrich faculty work are meaningful to higher education throughout the world, but are of critical importance to faculty members and institutional leaders themselves (Chism, Gosling \& Sorcinelli, 2010). An advantage to the burgeoning global academic environment is the increase in opportunities for communication and collaboration between and among international faculty development colleagues, which can stimulate the creation and sharing of new knowledge and fresh perspectives (Chism, Gosling \& 
Sorcinelli, 2010). It is imperative that attention be paid to developing the innovation competence of academics, if African universities are to act as a catalyst for socio-economic development (Kibwika, 2006). It is also a challenge to retain quality faculty (Asamoah \& Macklin, 2015). The number of quality faculty in Sub-Saharan Africa who are skillful, experienced, committed, and positioned to prepare students to become transformational leaders in Africa and the world at large is at a critical shortage. The shortage is significantly attributable to the brain drain of Africa's academics/scholars to the developed countries to seek greener pastures. A number of African countries lost a significant portion of their highly educated labor force (Capuano \& Marfouk, 2013) to overseas migration. The brain drain problem is compounded when considering women academics, since the numbers of women academics are lower and the stakes higher. Seeing women represented in leadership roles is a fundamental element for growth and development for women and girls (World Bank, 2007; Asamoah \& Mackin, 2015)

In Ugandan universities, three categories of staff exist, namely, the academic or teaching staff, the administrative staff, and the support staff (Kasule, Wesselink \& Mulder, 2016). According to the most recent data in 2017-2018, only $16 \%$ of the total staff have $\mathrm{PhD}$ qualifications (NCHE, 2018). However, there are some encouraging, if not mixed data, which point to faculty development being on an upward trend. According to the 2017-2018 NCHE State of Higher Education in Uganda report, staff development increased by 50 (2.7\%), and the percentage of the staff on $\mathrm{PhD}$ programs alone increased by $1.2 \%$ and masters by reduced by -30 $(-4.8 \%)$. Donors sponsored many of the teaching staff undergoing development, with a few being self-sponsored (NCHE, 2018). Faculty development continues to be a big challenge in all universities in Uganda, and there are myriad reasons why professional development for teaching staff at Ugandan universities should be considered a pressing need. 
First, there is ample concern as to the competence of teaching staff to deliver high-quality university service, including teaching, research and innovation, and engagement in community development activities (Kasule, Wesselink \& Mulder, 2016). The lack of training in pedagogy and classroom is one issue. In Uganda, the preferred teaching method is similr to the banking style, where the teacher holds all of the knowledge, and students are punished for critical thinking (Asamoah \& Mackin, 2015). Teaching staff lecture students, offering "didactic recitations from the lecturer as passive absorbers" (Asamoah \& Macklin, 2015, p. 9) and are provided intermittent self-study assignments that have little to do with the exams that are weighted heavily at the end of the semester (Akina, personal communication).

This unwillingness to co-create knowledge does not stop with the students. There is a serious lack of knowledge sharing and best practice offered among faculty. The lack of mentoring and apprenticeship stifles development in the teaching ranks:

Highly inadequate mentoring system in the academia is equally a problem to the required skillfulness of lecturers. For example, professors and well-experienced senior lecturers are supposed to select some junior lecturers and mentor and coach them in order to prepare them for the teaching and research business and for a smooth and well-prepared transition, a takeover when the professors are retired and also finished serving their contracts with the university. But this is not effectively done. The lack of this practice is not helping to build skillful and well-experienced lecturers who are able to perform to the expectation of the society (Asamoah \& Macklin, 2015, p. 9)

Next, as university teaching staff roles are becoming more complex, teaching staff should be provided with tools to develop the capability to cope with the added complexity (Kasule, Wesselink \& Mulder, 2016). Diverse professional development programs allow staff members to keep pace with educational innovations and to guarantee educational quality. Enacting deliberate policies that promote staff development and working toward building capacity in teaching, research, and service are viable solutions to this negative development trend. More emphasis should be placed on supporting staff at all levels, but in particular, the PhD level. 
Institutions should take up the mantle to recruit and retain $\mathrm{PhD}$ staff and offer incentives for staff development that include funding and this should be reflected in the institutional budgets.

(NCHE, 2018).

Putting in place a competent university teaching staff force is key for the realization of high quality university education that can spur socio-economic development (Kasule et al. 2014; Kropff, 2014). Kasule's (2015) dissertation specifically studied Uganda higher education and the "perceived importance of innovation competence, the actual level of innovation competence, the participation in and perceived effectiveness of innovation competence development activities, as well as the perceived influences of human resource management factors on innovation competence development" (Kasule, 2015, p. 119). Perhaps one way innovation competence can be enhanced among university teaching staff in Ugandan universities through the advancement of Kasule et al.s' (2014) five innovation competence domains:

1. innovating

2. knowledge society facilitating

3. collaboration and networking

4. higher education designing and developing

5. entrepreneurship

Kasule's domains may be useful from an African scholar perspective - and a specifically Ugandan framework - in addressing ways to assist teaching staff in Ugandan universities to perform their present and future university tasks.

In a time when there seems to be reluctance for professional training and development for university teaching staff, particularly in Sub Saharan Africa, (McAleese et al., 2013; Hamdan, 2011), the need to identify professional development activities that augment university teaching staff essential duties cannot be overstated (Henard \& Roseveare, 2012). As individual development and performance are intrinsically linked, this can be viewed as an organization 
culture opportunity in which organizations take a top down approach in recognizing that institutional performance will improve with individual development actions, but only if the culture supports it (Bierema,1996). Thus, Ugandan higher educational institutions need to offer targeted professional development programs to allow teaching staff members to keep up with educational innovations and to guarantee educational quality (De Rijdt, Dochy, Bamelis, and Van Der Vleuten, 2014). Senge (1990) notes that organizations must design infrastructure to support the learning, or systems, worldview, and that "ironically, by focusing on performing for someone else's approval, corporations create the very conditions that predestine them to mediocre performance. Over the long run, superior performance depends on superior learning" (p. 7). As such, participation in formal and informal professional development activities can immeasurably help the university teaching staff to develop the capability to improve individual performance and that of the university (De Rijdt, Dochy, Bamelis, and Van Der Vleuten, 2014).

\section{Gender Equitable Leadership Development}

According to Lwakabamba (2008) "leadership is a set of attitudes and practices, and is a way of working with people and a way of looking at what it means to work effectively in an institution" (p. 2). While Africa is witnessing a resurgence of interest in leadership rooted in indigenous values, much of the empirical research in this context has been conducted by western researchers, through western paradigms, for consumption by western audiences. (Bolden \& Kirk, 2009). It is clear that an understanding of African leadership has to be developed. Where leadership is a catalyst for social change and transformation, it is only where it is deeply rooted in African concepts of identity and community (Mbigi and Maree, 1995; Olojede, 2005; Prinsloo, 2000). Kirk, Bolden (2006) relate:

One thing that clearly emerges, however, is that the connotations of "African Leadership" are fundamentally emotive. It may cause people to be rightly wary of the importation of 
other models of leadership, which may be neo-colonialist by intent or effect, or indeed wary of the suggestion that outside models are superior in any way and that 'African leadership' through its naming is 'othered'. For the majority of participants, however, the term carries a positive ring, an endorsement of Africans who provide leadership in an Africa in which they take pride. A more geographically located statement like "Leadership in Africa" is certainly more neutral than "African leadership" which suggests leadership that resides in, and is owned by Africans. It will provoke less emotion, and that may be its strength, but for the same reason it may also be its weakness.

As it relates to developing male faculty to be more gender equitable leaders, the men themselves have an important role to play (Anicha, Burnett, \& Bilen-Green, 2015). Not only should they become "knowledgeable about their own positions of power and privilege" (Carlson, 2008; Cochran-Smith, 1995; Reason \& Broido, 2005), but they should also understand how sexism provides them with unearned "symbolic capital" (Bourdieu, 1986). Thus, it is important when developing faculty leaders, to not exclude men from the opportunity to learn how to assess inequities and cultivate essential gender competence skills.

If developing a leadership in Africa paradigm is difficult, then developing one that recognizes an African female perspective is even more elusive. The difficulty in definition is in large part due to the fact that when we talk about women's leadership, it is often held against the “idealized male" (Acker, 1990) who is presumably "white, western, and male" (Stead \& Elliott, 2009 , p. 164). This is called essentializing which is an inaccurate cognitive bias that sets women up for unrealistic expectations about how they behave as leaders (Bierema, 2016). The prevailing sentiment in the literature holds that there is no such thing as "women's leadership"—-just leadership — and instead of seeking a definition, we should be cognizant of the experience and progress of women leaders as the challenges they face are clear (Bierema, 2016). Moving towards gender consciousness, gender competence, and gender equity allows leaders to appreciate how "gendered power relations impact interpersonal dynamics, decisions, and 
development [as opposed to holding] gendered expectations of how women should lead ...[that] prevent women and organizations from benefiting from diverse approaches to leadership by both women and men" (Bierema, 2016, p. 132).

\section{Developing Leaders}

Given, as Day, Harrison, \& Halpin (2009) attest, that individual leader development occurs in the context of ongoing adult development, perhaps the best way to develop a leadership identity is to focus on development as much as leadership (Day, 2000). Development occurs in ongoing practice through day-to-day leadership activities, and can be a byproduct of formal leadership development training as participants reflect on their learning as they engage in leadership and observe what other leaders do to affect change (Day, Fleenor, Atwater, Sturm, \& McKee, 2014). Therefore, setting up formal leadership development programs in Ugandan academic settings that function more like educational opportunities than training sessions is an important endeavor (Hughes, 2018). Most urgently, however, is the idea that Ugandan leadership development must look like, and take cues from the social system in which it began. It must be rooted and grounded in the culture, as it "emerges out of the interactions between its members, [only] then by developing a capacity for critical inquiry into those interactions, members of that social system are better able to shape the kinds of leadership they are creating" (Kirk \& Bolden, 2006). For this reason, Ugandan leadership development should incorporate awareness raising reflexive processes (Kirk \& Bolden, 2006) such as mentoring and coaching.

Mentorship is "a professional, working alliance in which individuals work together over time to support the personal and professional growth, development, and success of the relational partners though the provision of career and psychosocial support” (National Academies of Sciences, Engineering, and Medicine, 2019, p. 2). Protégées typically benefit individually from 
the personal nature of the mentoring interaction, as they see leadership modelled in front of them. Mentoring also includes a measure of leader development in the training, professional development, sponsorship and networking opportunities provided. On an individual level, mentoring can stave off disillusionment, invigorate plateaued staff and provide psychosocial assistance at work, which clears up role ambiguity, role conflict and perceived environmental uncertainty (Carmel, 2015; Viator, 2001). As well, there are larger systemic and organizational benefits to mentoring, such as assisting with organization development, or planned change, and fostering goodwill and appreciation toward the organization by both mentors and mentees alike (Carmel, 2015; Viator, 2001).

Okurame (2008), in a study on Nigeria on mentoring in academia found that mentoring in African settings typically comes in the form of hierarchical mentoring, where mentors are older and more experienced than their protégés:

A common feature of these relationships is the great allegiance and respect accorded to mentors by their protégés. This is particularly in view of the African perspective that wisdom stems from old age. However, some negative connotations of mentors as Godfather exist, in general mentors are appreciated for giving direction to younger colleagues (Okurame, 2008, p 48-49). ).

Interestingly, Okurame (2008) also found that mentoring training was integral to the success of formal mentoring programs in Africa. His major finding noted that the training also needed to accentuate both gender sensitivity and cooperative interaction, to improve interaction and thwart interpersonal problems between men and women faculty dyads, and allay fears in such arrangements. Not only that, but the study surmised that training in this area will also aid in empowering the few senior female academics to be mentors to multiple female protégés (Okurame, 2008). 
A similarly advantageous leadership development activity is coaching. Coaching can be defined as "a deliberate process using focused conversations to create an environment for individual growth, purposeful action, and sustained improvement” (Homan \& Miller, 2008, p. 7). Similarly, the International Coach Federation (2017), define coaching as "partnering with clients in a thought-provoking and creative process that inspires them to maximize their personal and professional potential, which is particularly important in today's uncertain and complex environment" (p. 2). There is a sense that coaching helps individuals to increase self-awareness and self-confidence, garner new insight, practice responding to people and situations, and achieve their goals (Gander, Moyes \& Sabzalieva, 2014). Coaching is not as prevalent in academic settings as in business; however, since coaching flourishes in environments where the focus is on continuous improvement and achieving the best outcomes, it seems ripe for developing those in academic settings (Lordanou, Lech, \& Barnes, 2016, p. 145). Simply "having a coach to listen, support, and challenge their work can lead to a more satisfactory, well considered outcome for both an individual and their institution" (Lordanou, Lech, \& Barnes, 2016, p. 149).

Of the scant literature related to coaching women leaders (Peltier, 2010; Skinner, 2014) even is less related to coaching women leaders in higher education, and there is no literature currently among African universities. A South African study from Mshumpela (2019) on women entrepreneurs inform us that coaching aids in the perceived long-term impact on "selfconfidence, enhanced leadership skills, developed strategic thinking ability, improved marketing skills and enhanced organizing skills" (p. i). A significant part of the issue lies in the low numbers of female academics, and the patriarchal culture within academia. 
Still, coaching, as a developmental tool, can be an important part of introducing an aspiring researcher into successful careers in academia (Sorcinelli, 2000). Coaching is integral to creating a "robust leadership pipeline, with the ability to identify future male and female faculty leaders, accelerate their development, and bolster them for organizational change. It is suggested that coaching has become increasingly popular as a way to develop individual leaders as well as improve and measure organizational performance (Brunning, 2006). Whatever the reasons for leadership development - in preparation for planned change, in response to a leadership pipeline deficit, or as a way to stave off competition and changing demographics_-organizations should be adequately prepared for such an undertaking. (Leskiw \& Singh, 2007).

\section{Preparing for Uganda: Undertaking Transcultural Research}

The remainder of the article identifies the best practices, processes and systems in conducting transcultural research discussed through a compilation of literature. I add a conceptual framework as an aid for me and other researchers engaging in similar research. In overlaying Slimbach’s (2005) Transcultural Competencies with my own reflections and anticipations, I hope to emphasize the best practices for such collaborative processes involved in conducting action research internationally.

Slimbach's (2005) Transcultural Competencies outline concrete changes learners can expect as they engage in international research. Six competencies—ones I hope to attain through my research experience — are shown below and in Fig 1. The narrative that follows are my reflections on what I need to do to attain these ideals. 


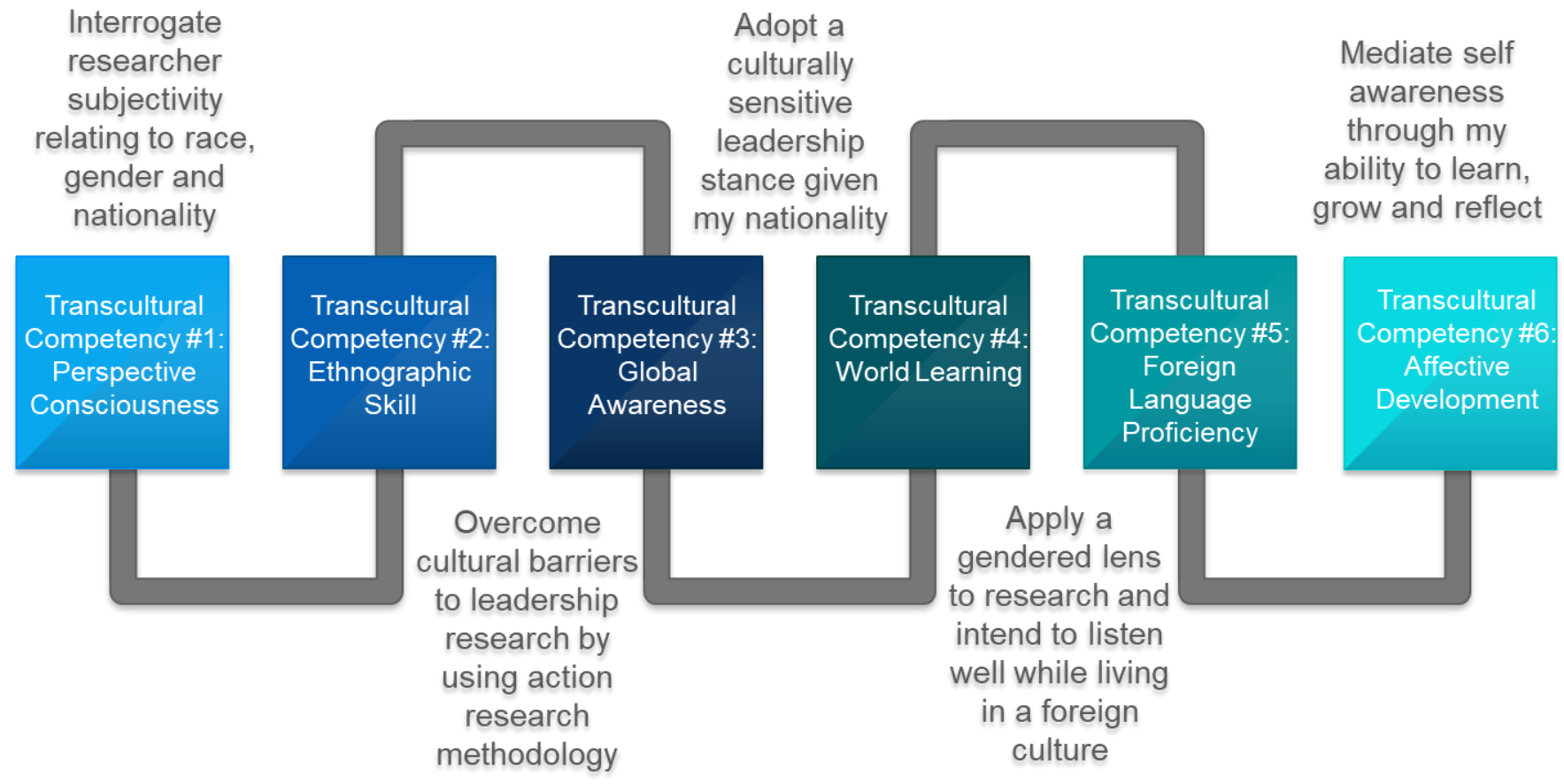

Figure 1 Adapted from Slimbach (2005) Transcultural Competencies

\section{Transcultural Competency \#1: Perspective Consciousness}

Slimbach's (2005) first Transcultural Competency is perspective consciousness, or the ability to question constantly the source of one's cultural assumptions and ethical judgments, leading to the habit of seeing things through the minds and hearts of others (p. 206). This is aligned with a recognition that I need to interrogate my own subjectivity relating to race, gender, and nationality.

I am a Black American woman, strongly influenced by feminist thinking that takes into account the intersection of race, class, gender, and ethnicity and its effect on an individual's life experiences and worldview. Thus, applying a gendered lens to research in a traditionally patriarchal African context could be fraught with risk. Although I research and teach in settings where I confront such power dynamics, I need to remain mindful that my views of power and authority will be different in an African context and global environment (Kasule, 2015) 
Glover (in Reddick, 1998) said, "a shared complexion does not equal a shared culture, nor does it automatically lead to friendships". The socio cultural issues that confront Black Americans when they come back to the African continent are delicate. Therefore, I am conscious of the continual need to interrogate my subjectivity, while listening and learning about African leadership, culture, and mores. I am also aware that I cannot not impose a Westernized view of leadership in my research, or as some are inclined to do, "portray African women as "a powerless group subject to poverty and ignorance, in contrast to Western women, who are portrayed as educated, modern, and free to make their own choices" (Curran, 2017).

\section{Transcultural Competency \#2: Ethnographic Skill}

Slimbach's (2005) second Transcultural Competency is Ethnographic skill, or the ability to observe carefully social behavior, manage stress, and establish friendships across cultures, while exploring issues of global significance, documenting learning, and analyzing data using relevant concepts (p. 206). I believe that by using an action research method, I can exemplify this competency.

Action research is the proposed methodology for this research study. This project intends to meld faculty development and gender equity to improve leadership outcomes and promote organization-wide culture change. Action research involves relevant stakeholders in an iterative process to define the problem, collect and analyze data, identify and implement interventions, and evaluate the result (Bierema, 2014). There is sparse research dedicated to this issue in Ugandan universities where these systems have tended to be gendered and unequal, with academic access and benefits denied to women (Assié-Lumumba, 2006). Thus, taking up research toward understanding and taking action on individual, group, and systemic gender issues seems both well timed and exigent. 
In addition, action research is innately political as a research methodology: gaining access, using data, disseminating, and publishing reports involve a balance of providing the organization with justification of what it wants with the researcher's own tacit personal justification for engaging in research activity (Coghlan \& Brannick, 2014). Fortunately, since action research is also adaptive work, none of these challenges is daunting. Built into the action research design of the project is the involvement of stakeholders throughout the process to provide needed checks and balances. This is a purposeful addition, as I will need the assistance of an active group of action researchers who will help with access to organizational knowledge and co-construction of meaning. This exciting undertaking will engage a qualitative action research project to understand the gender equity experience of Ugandan faculty, and to investigate the learning outcomes of implementing a faculty leadership development program based on gender equity principles.

\section{Transcultural Competency \#3: Global Awareness}

Slimbach's (2005) third Transcultural Competency is Global awareness, or a basic awareness of transnational conditions and systems, ideologies and institutions, affecting the quality of life of human and non-human populations, along with the choices confronting individuals and nations (p. 206). I am hyperaware of my nationality as a Black American.

In thinking of my nationality, I may also come across cultural issues as a Black American woman. Glover (quoted in Reddick, 1998) said, "a shared complexion does not equal a shared culture, nor does it automatically lead to friendships". The socio cultural issues that confront Black Americans when they come back to the African continent are delicate. Therefore, as a Black American woman, I will need to listen and learn about Africa, its leadership, culture, and mores, and be careful to not impose a Westernized view of leadership. I will not, as some are 
inclined to do, "portray African women as "a powerless group subject to poverty and ignorance, in contrast to Western women, who are portrayed as educated, modern, and free to make their own choices" (Curran, 2017).

\section{Transcultural Competency \#4: World Learning}

Slimbach's (2005) fourth Transcultural Competency is World learning: direct experience with contrasting political histories, family lifestyles, social groups, arts, religions, and cultural orientations based on extensive, immersed interaction within non-English speaking, nonAmericanized environments (Slimback, 2005, p. 207).

I am strongly influenced by feminist thinking that takes into account the intersection of race, class, gender, and ethnicity and its effect on an individual's life experiences and worldview, and I suspect that applying a gendered lens to research in a traditionally patriarchal African context could be fraught with risk. Although I research and teach in settings where I confront such power dynamics, I need to remain open to other views and mindful of the differences in power and authority in an African context and global environment. I desire, as in Chimamanda Ngozi Adichie's The Danger of a Single Story TED Talk, to “question my own beliefs and assumptions" (Adiche, 2009).

\section{Transcultural Competency \#5: Foreign Language Proficiency}

Slimbach's (2005) fifth Transcultural Competency is Foreign Language proficiency: a threshold-level facility in the spoken, non-verbal, and written communication system used by members of at least one other culture (p. 207).

The national language of Uganda is English, and classes are taught in English. Uganda is known for being English-friendly in business and education contexts, although many other languages could be spoken in the home. I have several Ugandan friends with whom I have no 
trouble communicating, and if I listen well, and am clear and distinct in the way I speak, I do not anticipate language being a barrier to communication.

\section{Transcultural Competency \#6: Affective Development}

Slimbach's (2005) sixth Transcultural Competency is Affective Development, or the capacity to demonstrate personal qualities and standards "of the heart" (e.g., empathy, inquisitiveness, initiative, flexibility, humility, sincerity, gentleness, justice, and joy) within specific intercultural contexts in which one is living and learning (Slimback, 2005, p. 207).

Before I embarked on my academic journey, I held the belief that the intent of teaching was about imparting knowledge on others - that it was about me being an expert in a particular area, and that "expertise" was to be shared with those in the classroom. I have come to subscribe to the constructivist approach where I help adult learners to construct knowledge through experience, and guide them as they make meaning and connections. Thus, the trip to conduct research is an extension of this constructive approach, where development of leaders is more about them, and much less about me. As an adult educator, my self-awareness as a leader and lifelong learner is mediated through my ability to learn, grow, and reflect. I anticipate my experience in Uganda will add breadth and depth to my life. In order to do so, I echo Kotter (1996) in remaining always hungry to learn more about how to enthuse, engage and empower those who follow. 


\section{References}

Adichie, C. N. (2009). The danger of a single story. Retrieved from https://www.ted.com/talks/chimamanda_ngozi_adichie_the_danger_of_a_single_story

Africa Human Development Report 2016. (2016, August 28). Retrieved from http://www.undp.org/content/undp/en/home/librarypage/hdr/2016-africa-humandevelopment-report.html

Amme, G., \& Agaba, J. (2014). Universities told to stop duplicating courses. Retrieved from http://www.newvision.co.ug/news/658082-universities-told-to-stop-duplicatingcourses.html

Anicha, C. L., Burnett, A., \& Bilen-Green, C. (2015). Men faculty gender-equity advocates: A qualitative analysis of theory and praxis. The Journal of Men's Studies, 23(1), 21-43.

Asamoah, M. K., \& Mackin, E. E. (2015). Breaking the Fetters of Higher Education in SubSaharan Africa. International Journal of Educational Administration and Policy Studies, 7(1), 6-16.

Asiimwe, S., \& Steyn, G. M. (2013). Obstacles hindering the effective governance of universities in Uganda. Journal of Social Sciences, 34(1), 17-27.

Asiimwe, S., \& Steyn, G. M. (2014). Building Blocks to Effective and Sustainable University Governance in Uganda. Journal of Social Sciences, 39(2), 135-147.

Assié-Lumumba, N. (2006). Empowerment of women in higher education in Africa: The role and mission of research (UNESCO Forum Occasional Paper Series Paper, Publication No. 11.

Bierema, L. L. (2014). Organization development: An action research approach. San Diego, CA: Bridgepoint Education, Inc.

Bierema, L. L. (2016). Women's leadership: Troubling notions of the "ideal"(male) leader. Advances in Developing Human Resources, 18(2), 119-136.

Bisaso, R. (2010) Organisational responses to public sector reforms in higher education in Uganda: a case study of Makerere University, Journal of Higher Education Policy and Management, 32:4, 343-351, DOI: 10.1080/1360080X.2010.491108

Bolden, R., \& Kirk, P. (2009). African leadership: Surfacing new understandings through leadership development. International Journal of Cross Cultural Management, 9(1), 69-86.

Brunning, H. (Ed.). (2006). Executive coaching: Systems-psychodynamic perspective. New York, NY: Karnac Books.

Capuano, S., \& Marfouk, A. (2013). African brain drain and its impact on source countries: What do we know and what do we need to know? Journal of Comparative Policy Analysis: Research and Practice, 15(4), 297-314. 
Carmel, R. G., \& Paul, M. W. (2015). Mentoring and coaching in academia: Reflections on a mentoring/coaching relationship. Policy Futures in Education, 13(4), 479-491.

Chism, N., Gosling, D., \& Sorcinelli, M. D. (2010). International faculty development. A guide to faculty development, 243-258.

Coghlan, D., \& Brannick, T. (2014). Understanding action research. Doing action research in your own organization, 43-62.

Curran, C. (2017). Women's Emancipation Movements. In G. R. Goethals, C. L. Hoyt, \& K. Christensen (Eds.), Women and leadership: History, theories, and case studies (p. 61). Great Barrington, MA: Berkshire Publishing Group.

Day, D. V. (2000). Leadership development: A review in context. Leadership Quarterly, 11, 581-613

Day, D. V., Fleenor, J. W., Atwater, L. E., Sturm, R. E., \& McKee, R. A. (2014). Advances in leader and leadership development: A review of 25 years of research and theory. The leadership quarterly, 25(1), 63-82.

Day, D., Harrison, M., \& Halpin, S. (2009). An integrative approach to leader development: Connecting adult development, identity, and expertise. New York, NY: Psychology Press

De Rijdt, C., Dochy, F., Bamelis, S., \& Van Der Vleuten, C. (2014). Classification of staff development programmes and effects perceived by teachers. Innovations in Education and Teaching International. doi:10.1080/14703297.2014.916543"

Frantz, J., Rhoda, A., Murdoch-Eaton, D. B., Sandars, J., Marshall, M., \& Burch, V. C. (2019). Understanding faculty development as capacity development: A case study from South Africa. African Journal of Health Professions Education, 11(2), 53-56.

Gander, M., Moyes,H., \& Sabzalieva, E. (2014) Managing your Career in Higher Education. Basingstoke: Palgrave.

Gender Pay Gap in Uganda. (2018, May 29). Retrieved July 15, 2018, from https://mywage.org/uganda/salary/gender-pay-gap-in-uganda

Heifetz, R. A., Grashow, A., \& Linsky, M. (2009). The practice of adaptive leadership: Tools and tactics for changing your organization and the world. Boston, MA: Harvard Business Press.

Howard, A. (2012). Towards a Global Knowledge Economy: Recent Achievements and Challenges. From https://www.knowledge-economy.net/uploads/documents/2012/ presentations/H.\%20ALPER\%20-\%20Towards\%20a\%20Global\%20Knowledge\% 20Economy.pdf 
Huffman, M. L., Cohen, P. N., \& Pearlman, J. 2010. Engendering change: Organizational dynamics and workplace gender desegregation 1975-2005. Administrative Science Quarterly, 55: 255-277

International Coach Federation.(2017). What is professional coaching? http://coachfederation.org /need/landing.cfm?ItemNumber $=978 \&$ navItemNumber $=567$.

Kasule, G. W. (2015). Professional development on innovation competence of teaching staff in Ugandan universities (Doctoral dissertation, Wageningen University).

Kasule, G. W., Wesselink, R., \& Mulder, M. (2014). Developing innovation competence profile for teaching staff in higher education in Uganda. Journal of Education, 2(2), 1-26.

Kasule, G.W., Wesselink, R., Noroozi, O. \& Mulder, M. (2015) The current status of teaching staff innovation competence in Ugandan universities: perceptions of managers, teachers, and students. Journal of Higher Education Policy and Management, 37:3, 330-343, DOI: 10.1080/1360080X.2015.1034425

Kasule, G. W., Wesselink, R., \& Mulder, M. (2016). Professional development status of teaching staff in a Ugandan public university. Journal of higher education policy and management, 38(4), 434-447.

Kermeliotis, T. \& Veselinovic, M. (2014). CNN. http://edition.cnn.com/2014/05/13/ business/numbers-showing-africa-entrepreneurial-spirit

Kibwika, P. (2006). Learning to make change: Developing innovation competence for recreating the African university of the 21st century (PhD Thesis, Wageningen University, Wageningen Academic Publishers).

Kirk, P., \& Bolden, R. (2006, June). African Leadership: Insights, meanings, and connotations. In Leadership and Management Studies in Sub-Sahara Africa Conference (pp. 26-28).

Knight, P., Tait, J., \& Yorke, M. (2006). The professional learning of teachers in higher education. Studies in Higher Education, 31(3), 319-339. doi:10.1080/03075070600680786

Kotter, J. P. (1996). Leading Change. Boston, MA: Harvard Business School Press

Kropff, M. J. (2014). Tertiary education: a prerequisite to meet global challenges. Regional Universities Forum for Capacity Building in Agriculture (RUFORUM), 8(9), 1- 4

Kwesiga, J. 2002. Women's access to higher education in Africa: Uganda's experience. Kampala: Fountain Publishers

Lordanou,L., Lech, A., and Barnes, V., (2016). Coaching in Higher Education. In C. Van Nieuwerburgh, Coaching in Professional Contexts, London: Sage, pp. 145-157.

Leskiw, S. L., \& Singh, P. (2007). Leadership development: learning from best practices. Leadership \& Organization Development Journal. 
MacLeod, Z. M. (2018). Thriving in Higher Education: Coaching Women Leaders (Doctoral dissertation, Fielding Graduate University).

Makerere University. 2004. The gender terrain at Makerere University. Kampala: Makerere University Press

Makerere University. (2017, June 14). Historical Background. Retrieved February 13, 2020, from https://www.mak.ac.ug/about-makerere/historical-background

Makerere University. (2004). The gender terrain at Makerere University. Kampala: Makerere

Mama, A. (2003). Restore, reform but do not transform: The gender politics of higher education in Africa. Journal of Higher Education in Africa/Revue de l'enseignement supérieur en Afrique, 101-125.

Mamdani, M. (2007). Scholars in the market place: The dilemmas of new-liberal reform at Makerere University, 1989-2005. Kampala: Fountain publishers.

Mannathoko, C.E. 1995. Gender, ideology and the state in Botswana's teacher education. $\mathrm{PhD}$ Thesis, School of Education, University of Birmingham.

Maseko, B. M., van Wyk, R., \& Odendaal, A. (2019). Team coaching in the workplace: Critical success factors for implementation. SA Journal of Human Resource Management, 17(1), 111.

McArt E.W., Brown J.K. (1990) The challenge of research on international populations: theoretical and methodological issues. Oncology Nursing Forum. 17, 2, 283-286.

Meier zu Selhausen, F. P. (2015). Women's empowerment in Uganda: colonial roots and contemporary efforts, 1894-2012 (Doctoral dissertation, Utrecht University).

Mezirow, J. (1981). A critical theory of adult learning and education. Adult education, 32(1), 324.

Morgan, P. (2005). The idea and practice of systems thinking and their relevance for capacity development. Maastricht: European Centre for Development Policy Management.

Muriisa, R. K. (2014). Rethinking the role of universities in Africa: Leadership as a missing link in explaining university performance in Uganda. Journal of Higher Education in Africa/Revue de l'enseignement supérieur en Afrique, 12(1), 69-92.

Mshumpela, B.S. (2019). The perceived long-term impact of group coaching on women entrepreneurs in South Africa (Doctoral dissertation).

Mugisha Baine, E.M. (2010). Privatisation of higher education in Uganda and the global gender justice ideal: uneasy bedfellows?. Educational Review, 62(3), 315-328.

Mundy, M.A., Kupczynski, L., Ellis, J.D., \& Salgado, R.L. (2012). Setting the standard for faculty professional development in higher Education. Journal of Academic and Business Ethics, 5, 1-9

National Academies of Sciences, Engineering, and Medicine (2019). Dahlberg M.L. \&ByarsWinston, A., editors. The Science of Effective Mentorship in STEMM. Washington (DC): 
National Academies Press (US). The Science of Mentoring Relationships: What Is Mentorship? Available from: https://www.ncbi.nlm.nih.gov/books/NBK552775/

National Council for Higher Education (NCHE). (2018). State of Higher Education in Uganda Report. Retrieved from https://www.unche.or.ug/the-state-of-higher-education-report-201718-compiled-by-nche/

NCHE (2018). The State of Higher Education Report 2017/18. Retrieved from https://www.unche.or.ug/the-state-of-higher-education-report-2017-18-compiled-by-nche/

Nica, E. (2013). The importance of leadership development within higher education. Contemporary Readings in Law and Social Justice, 5(2), 189-194.

Northouse, P. G. (2018). Leadership: Theory and practice ( $8^{\text {th }}$ ed.). Sage publications.

Odoi-Tanga, F. (2010). Politics, ethnicity and conflict in post independent Acholiland, Uganda 1962-2006 (Doctoral dissertation, University of Pretoria).

Okurame, D. E. (2008). Mentoring in the Nigerian academia: experiences and challenges. International Journal of Evidence Based Coaching \& Mentoring, 6(2).

Reddick, T. (1998). African vs. African-American. Retrieved from https://www.library.yale.edu/ fboateng/akata.htm

Senge, P. (1990). Peter Senge and the learning organization. Rcuperado de.

Shoukry, H. (2017). Coaching for social change. The SAGE handbook of coaching, 176-194.

Slimbach, R. (2005). The Transcultural Journey. Frontiers: The Interdisciplinary Journal of Study Abroad, 11, 205-230.

Sorcinelli, M. D. (2000). Principles of Good Practice: Supporting Early-career Faculty

Torvik, R. (2009). Why do some resource-abundant countries succeed while others do not? Oxford Review of Economic Policy, 25(2), 241-256.

Tyson, L. D. (2014, November 03). Why everyone benefits from closing the gender gap. Retrieved from https://www.weforum.org/agenda/2014/11/everyone-benefits-closinggender-gap

Viator, R. E. (2001). The relevance of transformational leadership to nontraditional accounting services: Information systems assurance and business consulting. Journal of Information Systems, 15(2), 99-125.

Wachira, K. (2014, May 09). Higher education challenges post-2015 - UNESCO. University World News. Issue No:319. Retrieved from http://www.universityworldnews.com/article.php? story=20140508162141672

Walumbwa, F. O., Avolio, B. J., \& Aryee, S. (2011). Leadership and management research in Africa: A synthesis and suggestions for future research. Journal of Occupational and Organizational Psychology, 84(3), 425-439. 
World Bank, World DataBank Data (2014) Unemployment, youth total. Available at: http://databank.worldbank.org/data/reports.aspx?source=2\&series=SL.UEM.1524.ZS\&coun try

World Bank. (2015) Overview: Nigeria. Available at: http://www.worldbank.org/en/country/nigeria/overview

World Bank (2016) Independent power projects in sub-Saharan Africa: Lessons from five key countries. Available at: https://openknowledge.worldbank.org/handle/10986/23970

World Economic Forum (2017). Global Gender Gap Index 2017. Retrieved from:

https://www.weforum.org/reports/the-global-competitiveness-report-2017-2018 